\title{
IMPLEMENTASI WILCOXON SIGNED RANK TEST UNTUK MENGUKUR EFEKTIFITAS PEMBERIAN VIDEO TUTORIAL DAN PPT UNTUK MENGUKUR NILAI TEORI
}

\author{
Windi Astuti ${ }^{1)}$, Muhammad Taufiq ${ }^{2)}$, Taofik Muhammad ${ }^{3)}$, \\ ${ }^{1,2,3)}$ Pendidikan Teknologi Informas FKIP Universitas Muhammadiyah Tasikmalaya \\ Email : windiastuti301@gmail.com ${ }^{1)}$, mtaufiq@umtas.ac.id ${ }^{2}$, taofik.muhammad@umtas.ac.id ${ }^{3)}$,
}

\begin{abstract}
Abstraksi
Mata pelajaran komputer dan jaringan dasar merupakan mata pelajaran wajib C2 di SMK4 Tasikmalaya, terutama untuk jurusan Teknik Komputer Jaringan dan Rekayasa Perangkat Lunak. Pemberian video tutorial dan materi berupa power point text digunakan untuk mengukur seberapa efektif dan berpa nilai kenaikannya ketika setelah diberikan video tutorial serta materi power point text dengan menggunakan pretest sebagai nilai awal dan pottest sebagai nilai akhir setelah diberikan treatment berupa video tutorial dan power point text. Sampel peneltian ini adalah kelas $X$ sebanyak 31 peserta didik, metode yang digunakan menggunakan One-Group pretestposttest Design dengan pretest dan posttest yaitu mengerjakan soal pilihan ganda sebanyak 20 soal. serta analisis data dan uji hipotesis menggunakan Wilcoxon Signed Rank Test. Hasil yang didapat dari penelitian ini adalah nilai pretest rata-ratanya adalah 66.29 dan rata-rata nilai posttest adalah 94.16 sesudah diberikan materi berupa video tutorial dan power point text dan sangat efektif dikarenakan $\mathrm{Hl}$ diterima yaitu hasil uji Wilcoxon menunjukan nilai Asymp. Sig nya adalah 0.0 kurang dari 0.5 yaitu terdapat perbedaan nilai pretest dan posttest pada mata pelajaran komputer dan jaringan dasar serta terdapat kenaikan nilai dengan mengguanakan uji gain ternormalisasi yaitu sebesar 0.96 yang dikategorikan tinggi.
\end{abstract}

Kata kunci : Wilcoxon Signed Rank Test, Video Tutorial, Power Point Text.

\begin{abstract}
Computer and Computer networking lesson is a required lesson in SMKN 4 Tasikmalaya. Especially for faculty of computer network engineering and software engineering. Providing video tutorials and theory in power point text form are used to measure the increase of the value and to measure how effective is after it is being given by using the pretest and the posttest as the final value. The sample of this survey was 31 students in grade 10. The method that used One-Group Pretest-Posttest Design. Data analysis and hypotheses was using method Wilcoxon Signed Rank Test. The average pretest result obtained from this survey was 66.29 and the average posttest value was 94.6 after the tutorials and the theory were given. This is very effective because Hypotheses $H$ is received when the Wilcoxon Signed Rank Test result show the Significant Value. The Significant value is 0.0 less than 0.5 which is, there are differences in pretest and posttest values in computer and basic network subject, and there is an increase in the value using the normalized gain test, which is 0.96 and is categorized as high.
\end{abstract}

Keywords : Wilcoxon Signed Rank Test, Video Tutorials, Power Point Text

\section{PENDAHULUAN}

Wili Solidayah (2015:2), Uji peringkat bertanda Wilcoxon digunakan untuk membandingkan nilai tengah suatu variable dari dua data data sampel berpasangan. Dalam uji peringkat bertanda Wilcoxon bukan hanya tanda yang diperhatikan, tetapi perbedaan antara sampel yang berpasangan tersebut. Uji modifikasi bertanda Wilcoxon berfungsi untuk menguji perbedaan antar data berpasangan, menguji komparasi antar pengamatan sebelum dan sesudah (before after) diberikan perlakuan dan mengetahui efektifitas suatu perlakuan.

Tes peringkat bertanda Wilcoxon adalah tes nonparametik yang dapat digunakan untuk menetukan apakah dua sampel dipenden dipilih dari populasi yang memiliki distribusi yang sama. Syaratnya yaitu: Data interval yang diordinalkan, satu sampel yang berhubungan dan dua sampel. Hal ini dapat digunakan sebagai alternatif untuk uji T Student pasangan itu ketika populasi tidak dapat diasumsikan terdistribusi secara normal atau data pada skala ordinal. 


\section{Efektifitas}

Silalahi, (2015:38) efektivitas berarti doing the right things atau mengerjakan pekerjaan yang benar. Efektivitas menunjuk pada keberhasilan pencapaian sasaran-sasaran organisasional, sehingga efektivitas digambarkan sebagai satu ukuran apakah manajer mengerjakan pekerjaan yang benar [2].

1. Dapat dikatakan efektif bila terjadi kenaikan nilai teori pada saat posttest setelah diberikan sebuah video tutorial dan power point text.

2. Dapat dikatakan efektif jika semua siswa mempunyai nilai yang positif setelah diberikan video tutorial dan power point text.

3. Dapat dikatakan efektif jika hasil uji Wilcoxon nilai Asymp. Sig nya adalah kurang dari 0.5.

4. Dapat dikatakan efektif apabila $\mathrm{H} 1$ diterima yaitu ada perbedaan nilai pretest dan posttest pada mata pelajaran Komputer dan Jaringan Dasar setelah diberikan sebuah video tutorial dan power point text

\section{Video Tutorial}

Parida (2019:15) video tutorial dapat diartikan sebagai video yang sengaja diciptakan oleh guru yang berisi materi pembelajaran lengkap dengan tujuan pembelajaran, uraian materi, soal-soal latihan dan evaluasi, serta kunci jawaban yang mana semua materi yang ditampilkan pada video dapat dicetak (print out) sebagai handout [3]. Media Video adalah media utama untuk mendokumentasikan kejadian actual dan membawanya kedalam kelas, video memberikan kesempatan pada siswa. Pembelajaran video tutorial memberikan kesempatan kepada siswa untuk mendiskusikan apa yang telah mereka saksikan secara bersama-sama, sedangkan dengan buku teks siswa hanya membaca saja tanpa melihat apa yang sedang terjadi.

\section{Power Point Text}

Rudi dan Cepi \& Maryatun (2014:13) "Microsoft PowerPoint adalah [4] program aplikasi presentasi yang populer dan paling banyak digunakan saat ini untuk berbagai kepentingan presentasi baik pembelajaran, presentasi produk, meeting, seminar, likakarya dan sebagainya.

Maryatun (2014:14) menyatakan bahwa "Microsoft PowerPoint adalah salah satu jenis program komputer yang tergabung dalam Microsoft Office yang digunakan untuk presentasi dan merupakan program berbasis multimedia" [4].

\section{Evaluasi \& Pengukuran}

Nilai dan pendidikan merupakan dua hal yang satu sama lainnya tidak dapat dipisahkan. Dalam proses ini, maka pendidikan dituntut untuk mampu mengarahkan manusia pad acara-cara pemilihan dan penilaian dengan sesuai. Nilai memiliki arti nilai (Valuing) yakni perbuatan menuju nilai yang tidak dapat dipisahkan dari keseluruhan dimensi pendidikan

\section{METODE PENELITIAN}

Penelitian ini merupakan jenis penelitian kuantitatif yang digunakan untuk menganalisis data pengukuran efektifitas pemberian video tutorial dan power point text untuk mengukur nilai teori terhadap mata pelajaran komputer dan jarinan dasar dengan menggunakan suatu uji yaitu uji Wilcoxon Signed Rank Test. Berikut adalah rumus uji Wilcoxon Signed Rank Test yang digunakan dalam penelitian yang nantinya akan menghasilakn data berupa deskriptif statistic, ranking pretest dan posttest, serta hasil uji Wilcoxon Signed Rank Test yang akan mehasilkan uji hipotesis apakah $\mathrm{H} 1$ atau Ho yang diterima, maka rumusnya dapat dilihat adalah sebagai berikut:

$$
\begin{gathered}
\mu W_{R}=\frac{n(n+1)}{4} \\
\sigma W_{R}=\sqrt{\frac{n(n+1)(2 n+1)}{24}-\frac{\sum t^{3}-\sum t}{48}} \\
Z_{w}=\frac{W_{R}-\mu W_{R}}{\sigma W_{R}}
\end{gathered}
$$

Keterangan:

$\begin{array}{ll}\mu \mathrm{wr} & : \text { wilcoxon range / rata-rata } \\ \mathrm{Sp} & : \text { ranking positif }\end{array}$

sn $\quad$ : ranking negatif 


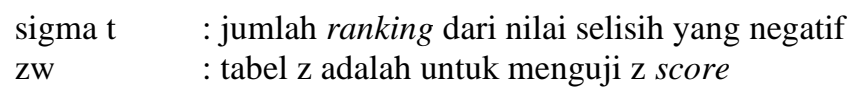

Sedangkan design yang digunakan adalah dalam penelitian ini adalah mengguanakan One-Group PretestPosttest Design, yaitu dalam desain ini terdapat pretest sebelum diberikan sebuah treatment yaitu berupa video tutorial dan materi dalam bentuk power point text. Desain One-Group Pretest-Posttest Design dapat dilihat pada gambar dibawah ini.

Keterangan :

$$
\mathrm{O}_{1} \mathrm{X} \mathrm{O}_{2}
$$

$\mathrm{O}_{1} \quad$ : nilai pretest (sebelum diberikan treatment)

$\mathrm{O}_{2} \quad$ : nilai posttest (setelah diberikan treatment)

Analisis hasil uji Gain Ternormalisasi pada penelitian ini menggunakan uji untuk melihat apakah terdapat kenaikan hasil belajar peserta didik setelah diberikan video tutorial dan power point text dan berada pada tingkatan apa rendah, sedang, atau tinggi kenaikannya. Untuk mengetahui nilai uji gain ternormalisasi maka rumus yang digunakan dalam jurnal oleh Agustina (2016) adalah sebagai berikut :

$$
N-\text { Gain }=\frac{\text { Skor Posttest }- \text { Skor Pretest }}{\text { Skor Maksimum }- \text { Skor Pretest }}
$$

Hasil Skor gain ternormalisasi (N-Gain) dapat diklasifikasikan menjadi tiga kategori yaitu sebagai berikut:

Tabel 3. Klasifikasi Uji Gain Ternormalisasi

\begin{tabular}{|l|l|}
\hline Nilai N Gain & Keterangan \\
\hline$N$-Gain $>0,70$ & Tinggi \\
\hline $0,30<N$-Gain $>0,70$ & Sedang \\
\hline$N$-Gain $<0,30$ & Rendah \\
\hline
\end{tabular}

\section{HASIL PENELITIAN DAN PEMBAHASAN}

Deskripsi Efektifitas Pemberian Video Tutorial Dan Power Point Text Untuk Mengukur Nilai Teori Mata Pelajaran Komputer Dan Jaringan Dasar Menggunakan Wilcoxon Signed Rank Test

Efektifitas pemberian video tutorial dan power point text dapat dikatakan efektif apabila terdapat kenaikan dari nilai pretest ke nilai posttest, serta dilihat dari uji Wilcoxon apakah $\mathrm{H} 1$ diterima dan $\mathrm{H} 0$ ditolak, H1 diterima jika terdapat perbedaan nilai dari pretest dan posttest, kemudian dilihat dari uji gain ternormalisasi jika klaisifikasi nya lebih dari 0.7 dan kurang dari 1.0 maka dapat dikatakan efektif karena berada pada kategori tinggi. Pada dasarnya penelitian ini melakukan pembuatan RPP, penyusunan kisi-kisi soal, pembuatan soal, validasi kepada ahli materi serta validasi terhadap ahli media, kemudian melaksanakan pretest, memberikan soal pretest, pemberian treatment berupa video tutorial dan power point text, melaksanakan posttest dan yang terakhir adalah analisis data.

Hasil akhir pengukuran nilai tentang implementasi jaringan dengan memberikan video tutorial dan power point text menggunakan pretest dan posttest pada penelitian ini adalah $\mathrm{H}_{1}$ diterima dikarenakan pada pengukuran nilai ini terdapat pengaruh setelah diberikan video tutorial dan materi yang diberikan dalam bentuk power point text untuk kelas yang menjadi sampel. Ini sesuai dengan penelitian sebelumnya kajian oleh Regina Salmadina Rauf (2019) yang berjudul "Implementasi Wilcoxon signed rank T test untuk mengukur efektifitas kebijakan reward dalam meningkatkan kinerja kerja karyawan di restaurant siap saji” yang menunjukan rekapitulsi sebelum diberikan reward dari 122 data sampel yang ada adalah 70.96 dan meningkat setelah diberikan reward dari 122 data menjadi 70.96. Dilihat dari penelitian sebelumnya maka dapat disimpulkan bahwa pemberian video tutorial dan power point text memberikan pengaruh serta lebih efektif, karena rata-rata pretest nya adalah 66.29 sedangkan setelah diberikan video tutorial dan power point text kemudian dilakkan posttest maka rata-rata nya adalah 94.19. 
Tabel 4. Hasil Penilaian Ahli Media

\begin{tabular}{|c|c|c|c|c|c|}
\hline \multirow[t]{2}{*}{ Indikator Pembelajaran } & \multirow[t]{2}{*}{ Nomer Soal } & \multirow[t]{2}{*}{ Indikator Berpikir Kritis } & \multicolumn{3}{|c|}{ Keterangan } \\
\hline & & & Sesuai & Kurang Sesuai & Tidak Sesuai \\
\hline \multirow[t]{8}{*}{ Memahami pengertian, dan penjelasan dari jenis-jenis topologi jaringan } & 1 & Menjawab pertanyaan & $\mathrm{v}$ & & \\
\hline & 3 & Memfokuskan pertanyaan & $\mathrm{v}$ & & \\
\hline & 5 & Memfokuskan pertanyaan & $\mathrm{v}$ & & \\
\hline & 6 & Menjawab pertanyaan & $\mathrm{v}$ & & \\
\hline & 7 & Menjawab pertanyaan & $\mathrm{v}$ & & \\
\hline & 8 & Menjawab pertanyaan & $\mathrm{v}$ & & \\
\hline & 9 & Mengobservasi dan menjawab pertanyaan & & $\mathrm{v}$ & \\
\hline & 11 & Menjawab pertanyaan & & $\mathrm{v}$ & \\
\hline \multirow[t]{3}{*}{ Menjelaskan proses dan mengidentifikasi cara membangun jaringan } & 2 & Menjawab pertanyaan & $\mathrm{v}$ & & \\
\hline & 4 & Menjawab pertanyaan & $\mathrm{v}$ & & \\
\hline & 19 & Menjawab pertanyaan & $\mathrm{v}$ & & \\
\hline \multirow[t]{4}{*}{ Memahami dan menjelaskan tentang IP Address } & 14 & Menjawab pertanyaan & $\mathrm{v}$ & & \\
\hline & 15 & Menghitung dan menjawab pertanyaan & & $\mathrm{v}$ & \\
\hline & 16 & Menghitung dan menjawab pertanyaan & $\mathrm{v}$ & & \\
\hline & 10 & Menjawab pertanyaan & $\mathrm{v}$ & & \\
\hline \multirow[t]{6}{*}{ Sharing Data } & 12 & Praktik dan menjawab pertanyaan & & $\mathrm{v}$ & \\
\hline & 13 & Menjawab pertanyaan & $\mathrm{v}$ & & \\
\hline & 17 & Menjawab pertanyaan & $\mathrm{v}$ & & \\
\hline & 18 & Menghtiung dan menjawab pertanyaan & $\mathrm{v}$ & & \\
\hline & 20 & Praktik dan menjawab pertanyaan & & $\mathrm{v}$ & \\
\hline & 21 & Menjawab pertanyaan & $\mathrm{v}$ & & \\
\hline
\end{tabular}

Tabel 5. Hasil Penilaian Ahli Materi

\begin{tabular}{|c|c|c|c|c|c|c|c|c|c|c|c|c|c|c|c|c|c|c|c|c|}
\hline \multirow[t]{2}{*}{ Aspek yang ditelaah } & \multicolumn{20}{|c|}{ Butir Soal } \\
\hline & 1 & 2 & 3 & 4 & 5 & 6 & 7 & 8 & 9 & 10 & 11 & 12 & 13 & 14 & 15 & 16 & 17 & 18 & 19 & 20 \\
\hline 1. Soal sesuai dengan $\mathrm{KD}$ yang dicapai & V & V & $\sqrt{ }$ & V & V & V & V & V & V & V & V & V & V & V & V & $\sqrt{ }$ & V & V & V & V \\
\hline 2. Soal sesuai dengan indikator yang diukur & V & V & $\sqrt{ }$ & V & V & V & V & V & V & V & V & $\sqrt{ }$ & V & V & $\mathrm{V}$ & V & V & V & V & V \\
\hline 3. Pilihan jawaban homogen dan logis & V & V & V & V & V & V & V & V & V & V & V & V & V & V & V & V & V & V & V & V \\
\hline 4. Hanya ada satu kunci jawaan yang tepat & V & V & V & V & V & V & V & V & V & V & V & V & $\mathrm{V}$ & V & $\mathrm{V}$ & V & V & V & V & V \\
\hline 5. Soal sesuai dengan ranah kognitif yang diukur & V & V & V & V & V & V & V & V & V & V & V & V & V & V & V & V & V & V & V & V \\
\hline 1. Pokok soal dirumuskan dengan jelas & V & V & V & V & V & V & V & V & V & V & V & v & V & V & V & V & V & V & V & V \\
\hline 2. Adanya petunjuk yang jelas tentang cara pengerjaan soal & V & V & V & V & V & V & V & V & V & V & V & V & V & V & V & V & V & V & V & V \\
\hline 3. Pokok soal tidak memberikan petunjuk kunci jawaban & V & V & V & $\sqrt{ }$ & V & V & V & V & V & V & V & V & V & V & V & $\sqrt{ }$ & V & V & V & V \\
\hline 4. Pokok soal tidak memberikan pernyataan negatif ganda & V & V & $\sqrt{ }$ & V & V & V & V & V & V & V & V & V & V & V & V & V & V & V & V & V \\
\hline 5. Gambar/grafik/tabel/diagram yang digunakan pada soal disajikan dengan jelas & V & V & V & V & V & V & V & V & V & V & V & V & V & V & V & V & V & V & V & V \\
\hline 6. Panjang rumusan soal relatif sama & V & V & V & V & V & V & V & V & V & V & V & V & V & V & V & V & V & V & V & V \\
\hline $\begin{array}{l}\text { 7. Pilihan jawaban berbentuk angka atau waktu disusun berdasarkan besar } \\
\text { kecilnya angka atau kronoligis kejadian }\end{array}$ & V & V & V & V & V & V & V & V & V & V & V & V & V & V & V & V & V & V & V & V \\
\hline 8. Butir soal tidak bergantung jawabannya dengan soal sebelumnya & V & V & $\sqrt{ }$ & V & $\mathrm{V}$ & V & V & V & V & V & V & V & V & V & V & V & V & V & V & V \\
\hline A. BAHASA & & & & & & & & & & & & & & & & & & & & \\
\hline 1. Menggunakan bahasa yang sesuai dengan kaidah Bahasa Indonesia & V & V & $\sqrt{ }$ & V & V & V & V & V & V & V & V & V & V & V & V & V & V & V & V & V \\
\hline 2. Menggunakan bahasa yang komunikatif & $\sqrt{ }$ & V & $\sqrt{ }$ & V & $\mathrm{V}$ & V & V & V & $\sqrt{ }$ & V & V & V & V & V & $\sqrt{ }$ & V & V & V & $\sqrt{ }$ & V \\
\hline $\begin{array}{l}\text { 3. Pilihan jawaban tidak menggunakan kelompok kata yang sama, kecual } \\
\text { merupakan satu kesatuan pengertian }\end{array}$ & ii $\sqrt{ }$ & V & V & V & V & V & V & V & V & V & V & V & V & V & V & V & V & V & V & V \\
\hline 4. Menggunakan kalimat jelas dan mudah dimengerti & $\sqrt{ }$ & V & V & V & V & V & V & V & V & V & V & V & V & V & V & V & V & V & V & V \\
\hline
\end{tabular}


Table 6. Hasil Uji Wilcoxon

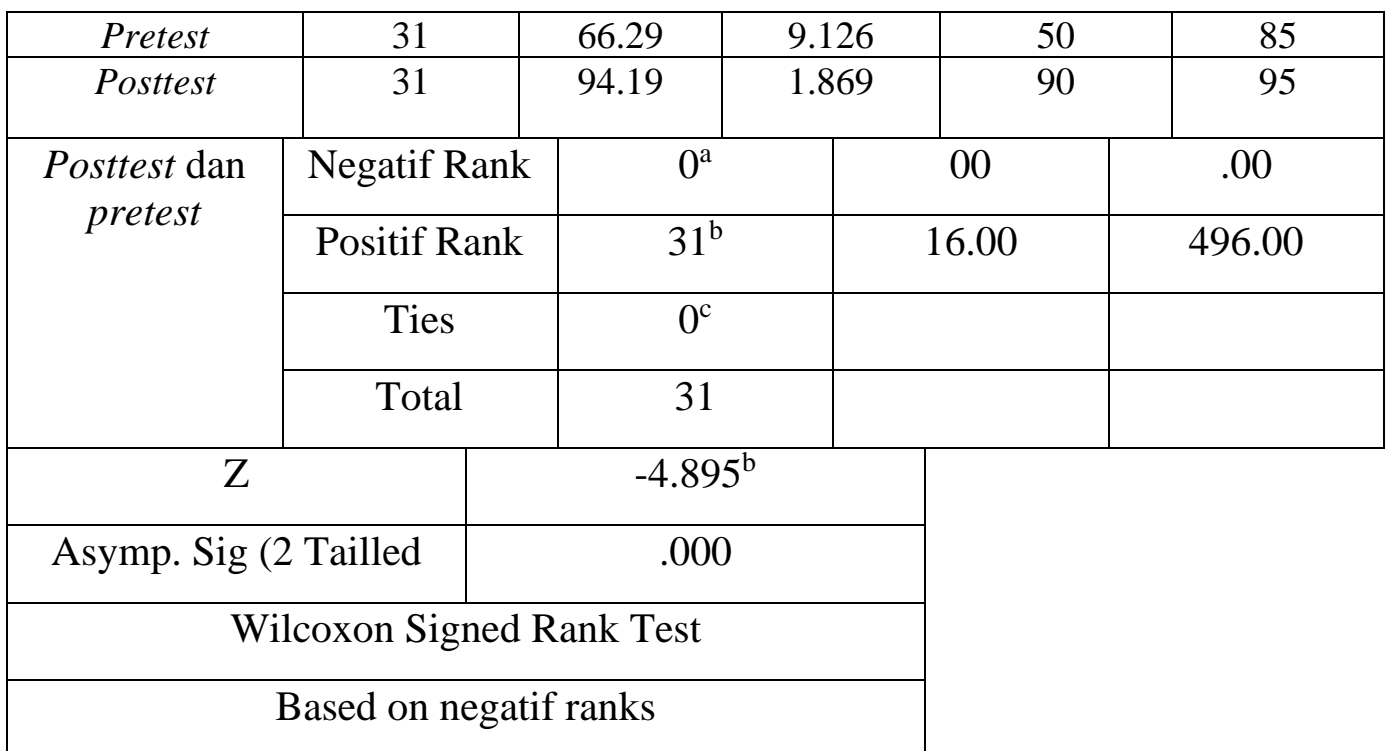

Tabel 7. Hasil Uji gain ternormalisasi

\begin{tabular}{|c|c|c|}
\hline No Resp & Gain score kelas eksperimen TKJ & Keterangan \\
\hline 1 & 0.67 & Sedang \\
\hline 2 & 1.00 & Tinggi \\
\hline 3 & 1.00 & Tinggi \\
\hline 4 & 1.00 & Tinggi \\
\hline 5 & 1.00 & Tinggi \\
\hline 6 & 1.00 & Tinggi \\
\hline 7 & 1.00 & Tinggi \\
\hline 8 & 1.00 & Tinggi \\
\hline 9 & 1.00 & Tinggi \\
\hline 10 & 1.00 & Tinggi \\
\hline 11 & 1.00 & Tinggi \\
\hline 12 & 1.00 & Tinggi \\
\hline 13 & 1.00 & Tinggi \\
\hline 14 & 1.00 & Tinggi \\
\hline 15 & 1.00 & Tinggi \\
\hline 16 & 1.00 & Tinggi \\
\hline 17 & 1.00 & Tinggi \\
\hline 18 & 1.00 & Tinggi \\
\hline 19 & 1.00 & Tinggi \\
\hline 20 & 1.00 & Tinggi \\
\hline 21 & 1.00 & Tinggi \\
\hline 22 & 0.50 & Sedang \\
\hline 23 & 1.00 & Tinggi \\
\hline 24 & 1.00 & Tinggi \\
\hline 25 & 1.00 & Tinggi \\
\hline 26 & 0.75 & Tinggi \\
\hline 27 & 0.86 & Tinggi \\
\hline 28 & 1.00 & Tinggi \\
\hline 29 & 1.00 & Tinggi \\
\hline 30 & 1.00 & Tinggi \\
\hline 31 & 0.86 & Tinggi \\
\hline Jumlah & 29.63 & \\
\hline \multicolumn{2}{|l|}{ Rata2 } & Tinggi \\
\hline
\end{tabular}

Peningkatan kemampuan belajar peserta didik yang diperoleh dari hasil uji gain ternormalisasi menunjukan nilai rata-rata nilai yang menjadi sampel mengalami peningkatan sebesar 0,96 yang masuk pada kategori tinggi. 
Hal ini tentunya ada perbedaan ketika kelas eksperimen diberikan video tutorial dan materi implementasi jaringan berupa power point text. Penelitian ini membuktikan bahwa pengukuran untuk mengetahui efektifitas pemberian video tutorial dan power point text terhadap mata pelajaran komputer dan jaringan dasar dapat berpengaruh dengan menggunakan pengukuran dan analisis data menggunakan Wilcoxon Signed Rank Test tentang Implementasi Jaringan.

\section{KESIMPULAN}

Berdasarkan penelitian yang telah dilakukan bahwa pemberian video tutorial dan materi berupa power point text terhadap mata pelajaran komputer dan jaringan dasar adalah, hal ini dikarenakan dilihat dari rata-rata nilai pretest adalah 66.29 sedangkan hasil posttest setelah diberikan treatment berupa video tutorial dan power point text rata-ratanya adalah 94.19 serta terdapat peningkatan nilai dai hasil uji gain ternormalisasi sebesar $0.96 \%$ yang dikategorikan tinggi, kemudian dari hasil uji Wilcoxon signed rank test menunjukan bahwa $\mathrm{H} 1$ adalah diterima dan H0 adalah ditolak dikarenakan Asymp. Sig nya adalah 0.0 dan kurang dari 0.5 yaitu terdapat perbedaan nilai pretest dan posttest pada mata pelajaran Komputer dan Jaringan Dasar setelah diberikan sebuah video tutorial dan power point text.

\section{DAFTAR PUSTAKA}

[1]. Wili Solidayah, Siti Sunendiari, Lisnur Wachidah, 2015, Uji Modifikasi Peringkat Bertanda Wilcoxon Untuk Masalah Dua Sampel Berpasangan, Universitas Islam Bandung, Bandung.

[2]. Silalahi, 2015, Asas-asas Manajemen, Bandung: Refika Aditama.

[3]. Parida, Sahono, Sapri, 2019, Pengaruh pembelajaran video tutorial terhadap prestasi belajar, Universitas Bengkulu.

[4]. Maryatun, 2015, pengaruh penggunaan media program microsoft powerpoint terhadap hasil belajar strategi promosi pemasaran mahasiswa semester 2 program studi pendidikan ekonomi universitas muhammadiyah metro tahun ajaran 2014/2015, Universitas Muhammadiyah Metro.

[5]. Sugiyono, 2016, Metode Penelitian Kuantitatif, Kualitatif, dan R\&D, Bandung, $\quad$ Penerbit Alfabeta

\section{BIODATA PENULIS}

Windi Astuti memperoleh gelar sarjana pendidikan (S.Pd) Program Studi Pendidikan Teknologi Informasi Universitas Muhammadiyah Tasikmalaya lulus pada tahun 2020.

Ir. Muhammad Taufiq, memperoleh gelar sarjana Teknik Perminyakan (S.T) kemudian melanjutkan studi program magister manajemen dan magister informatika (M.Kom) saat ini sebagai Staf Pengajar program Studi Teknologi Informasi Universitas Muhammadiyah Tasikmalaya.

Taofik Muhammad, memperoleh gelar sarjana pendidikan (S.Pd) kemudian melanjutkan studi program magister system informasi (M.Kom) saat ini sebagai kepala program studi pendidikan teknologi informasi dan dosen tetap Universitas Muhammadiyah Tasikmalaya. 